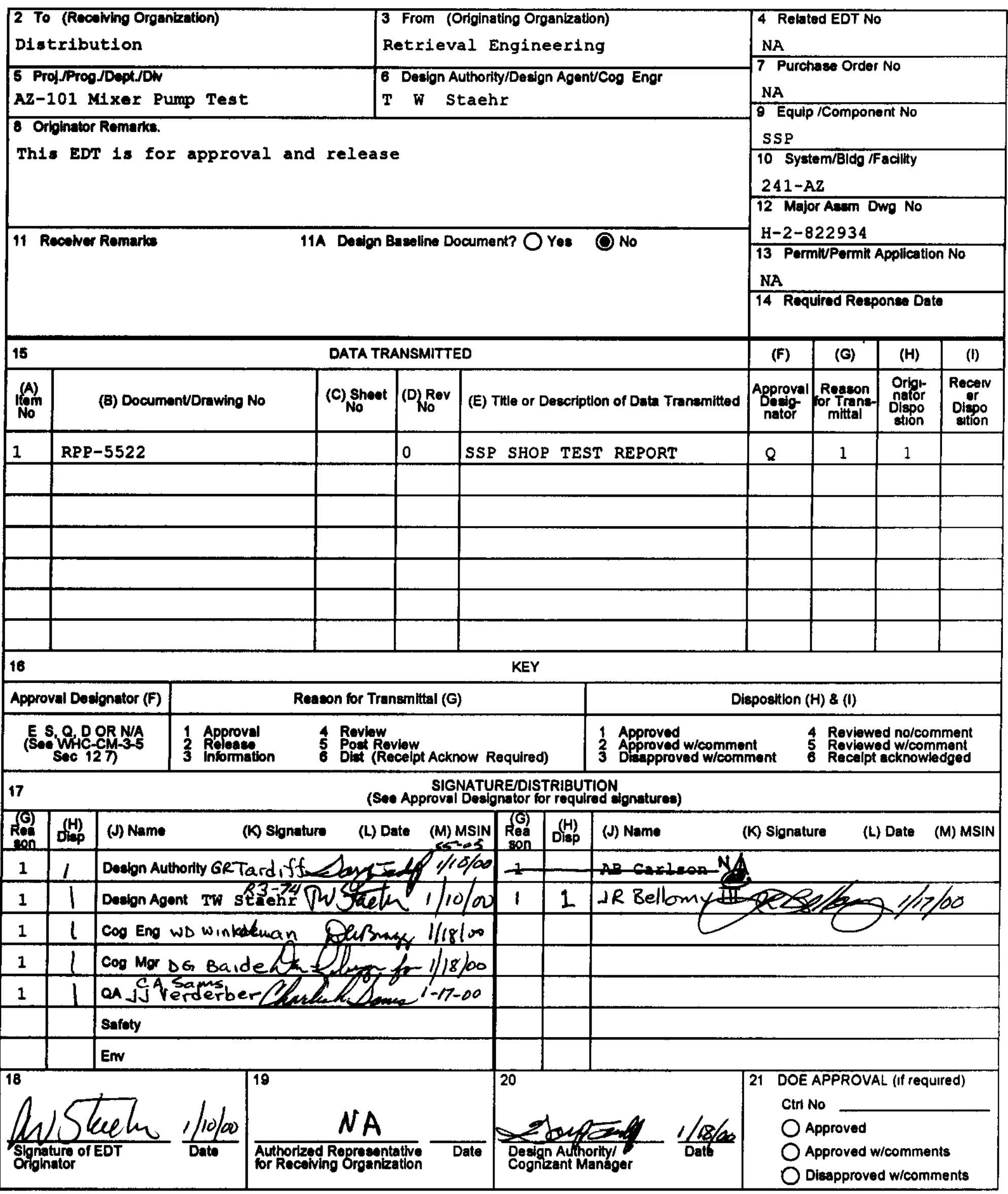




\section{Suspended Solids Profiler Shop Test Report}

T W Staehr

COGEMA Enguneering Corp , Ruchland, WA 99352

U S Department of Energy Contract DE-AC06-96RL13200

EDT/EGN 628649

UC 2030

Org Code 82300

B\&R Code EW02J2040

Charge Code CACN 106838

Total Pages 16

Key Words Tank AZ-101, suspended solids profiler, shop test, mixer pumps

Abstract. The Suspended Solids Profiler (SSP) instrument is planned to be installed in the AZ-101 tank to measure suspended solids concentrations during mixer pump testing The SSP sensor uses a reflectance measurement principle to determine the suspended solids concentrations The purpose of this test is to provide a documented means of verifying hat the functional components of the SSP operate properly

TRADBMARK DISCLAIMGR. Reference herein to any specific commercial product, proceas, or service by trade name trademark, manufincture or otherwise, does not necensenly constrtute or imply its endorsement, recommendation, or favoring by the United Statos Government or any agency theroof or its contractors or subcontractors

Prnited in the United States of Amence. To obtain copies of this document, contact WHC/BCS Document Control Services PO Box 1970 Malatop H6-08, Richland WA 99352, Phone (509) 3722420 Fax (509) 376-4989
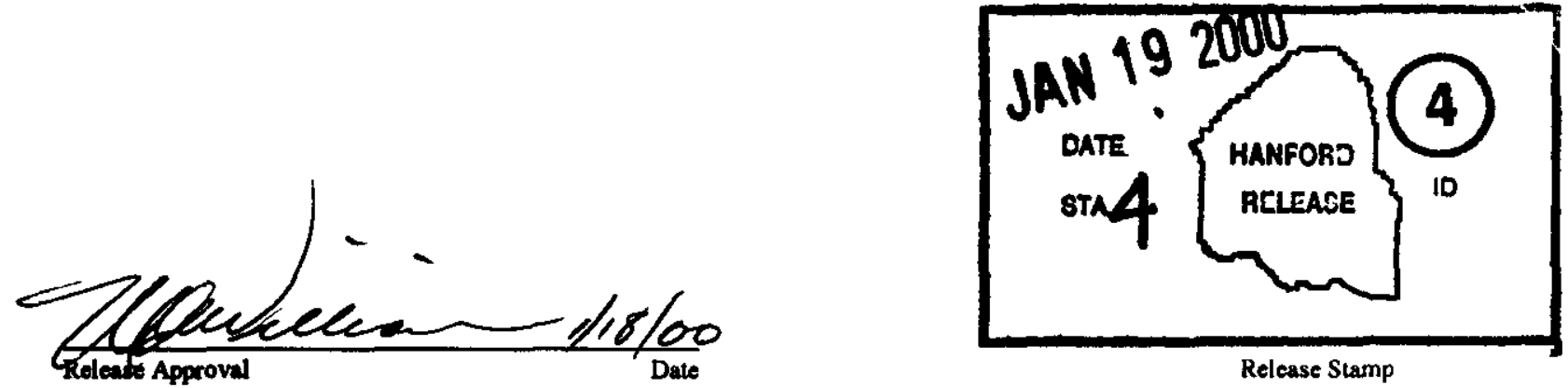


\title{
Suspended Solıds Profiler Shop Test Report
}

\author{
December 1999
}

T W Staehr COGEMA Engineerıng Corporation

Ruchland, Washington

Prepared for

U S Department of Energy

Office of River Protection

Ruchland, Washington 


\section{CONTENTS}

10 INTRODUCTION 1

20 TEST EQUIPMENT 2

21 SUSPENDED SOLIDS PROFILER 2

22 Data AcQuistTon SYSTEM 2

23 TEST SIMULANT 2

30 DESCRIPTION OF TEST

31 SSP CONFIOURATION

32 SSP PROFILINO OPERATION

33 SUSPENDED SOLIDS READING CALIBRATION

34 Elevation Calibration

35 Wash RING FunCtional OPERATION TESTING 5

40 TEST RESULTS 6

41 Manual Operation

42 AUTOMATIC OPERATION

43 SUSPENDED Solids REading Calibration

44 Elevation Reading Calibration

441 Distance Measurement 8

442 SSP Rotary Dial Setting Calıbration 8

443 Computer Screen Probe Depth Reading Calibration 10

45 SPRAY WASH SYSTEM

50 CONCLUSIONS AND RECOMMENDATIONS 12

APPENDIX A $\quad$ A-1

APPENDIX B $\quad$ B-1 


\section{INTRODUCTION}

This report documents the results of a shop test performed to venfy the functional operation and calibration of the Mt Fury Suspended Solids Profiler (SSP) The profiler is used commercially for the monitoning and control of clarifiers and thickeners in waste treatment, mining, pulp and paper, and other industrial processing facilities The SSP is planned to be tested dunng the Tank AZ-101 Mixer Pump Test to determine its applicability in DST tank retrieval operations by measuring waste slurry concentrations at vanous elevations after the mixer pumps have been operated

The test was performed under HNF-3562, Rev 0, "Suspended Solids Profiler Shop Test Procedure", including additional requirements per ECN-656970 Testıng was performed in the 306 bulding located in the 300 area of the Hanford Site from November 17, 1999 through December 2, 1999 The Test Procedure is attached as Appendix A to this report The team performing the test included the following

$\begin{array}{lll}\text { Tom Staehr } & - & \text { Test Director and Recorder } \\ \text { Graham Maclean } & - & \text { Test Engineer } \\ \text { Mike Wingfield } & - & \text { Quality Control/ Witness } \\ \text { Tom Clark } & - & \text { Authorized Inspector/ Oversight }\end{array}$




\section{TIST EQUIPMENT}

\section{SUSPENDED SOLIDS PROFILER}

The SSP is a microprocessor based suspended solids sensor used commercially for the control of clarifiers and thickeners in waste treatment facilities by measuring the turbidity versus depth and by determining the depth of the sludge blanket The sensor is completely solid state and uses a reflectance measurement principle with built in color and ambient light compensation, to determine suspended solids concentrations The sensor range is from 5 to $100,00 \mathrm{ppm}$ with a resolution of 5 ppm, or $1 \%$ of reading, whichever is greater A stepping motor dnven cable reel controls the sensor location In normal operation, the sensor is lowered to a preset elevation where the first of twenty equal spaced readings is taken The sensor is then automatically lowered to take a reading at each of the remainıng nineteen elevations After the final reading the sensor will be retracted to the glove box enclosure Digital rotary switches are used to set upper and lower depths to be profiled, a solids threshold for determinıng sludge blanket depth, profile tıme intervals, and other parameters

An enclosure assembly has been specially fabricated to house the SSP The assembly consists of a flanged bottom to attach to the tank nser, a ball valve used for shielding the probe when not in use, a glove box for ease in replacement of the probe, and a NEMA enclosed electronics box

\section{DATA ACQUISITION SYSTEM}

For this testıng, a personal computer was connected to the SSP via an RS232 serial interface The DATA_PRO software package provided by the Mt Fury Company was used to display and store the SSP data as well as provide system configuration and diagnostic information As DATA_PRO runs it generates daily data files and stores them in the same directory that the program is in Each data file will contain one day's data, and will typically contain $10 \mathrm{~K}-100 \mathrm{~K}$ bytes data The program will store from 1-99 days of data

\section{TEST SIMULANT}

Two waste simulant slurries were used for testing the SSP Both simulants were onginally prepared for other tests The first one contained equal moles of $\mathrm{Al}(\mathrm{OH})_{3}$ and $\mathrm{FE}(\mathrm{OH})_{3}$ in a $\mathrm{NaNO}_{3}$ solution This slurry was used in a test column that approximated tank waste depths The second slurry was manufactured to duplicate the PUREX process waste, which was discharged into tank Double shell tanks AZ101 and AZ-102 The composition and particle size of the slurry closely matched core sample data This second slurry was used to calibrate the profiler readings 


\section{DESCRIPTION OF TEST}

The objective of the SSP shop test was to verify the functionality of the SSP and that outputs agree with predetermined test values The test also served as a shop acceptance test prior to installing the SSP on Tank AZ-101 The profiler instrument was installed on a catwalk approximately 35 feet above floor level to approximate the distance the probe would have to travel when installed in tank AZ-101 The actual distance required in tank AZ-101 is closer to 60 feet, however, a clear span of that height was not avallable An 8-foot tall column made up of 2 sections of 12 inch diameter clear PVC pipe was filled with Al-Fe waste simulant and located under the SSP to represent the tank Power and signal cables were fabricated to link the profiler to a power supply and a personal computer (PC) on the operatıng deck Manual operation of the SSP was controlled locally through a control knob located in the SSP electronics box Automatic operation of the SSP was controlled remotely through a manual rake' switch located at the PC

The overall test is broken down into several separate phases as described in the following sections

\section{SSP CONFIGURATION}

This phase of testing includes configuring the SSP by inputting test settings per the manufacturers instructions, and then operating the SSP to compare settings and actual measured values Rotary dials in the SSP electronics box are used to dial in the desired settings The basic settings required for SSP operation testing are described below

DIST TO WATER This setting is the distance from the probe in the fully retracted position to the position of the probe when making its first profile measurement The setting is calculated by taking the distance from the bottom of the probe in its retracted position to the water (or waste) surface and then adding an additional 07 feet (the length of the probe) to ensure that the sensor is fully submerged when making its first reading

WATER DEPTH This setting is the total span distance that will be profiled The profiler will take a total of 20 equally spaced readings over this span If the entire depth of the waste is to be profiled the entered depth should be the distance from the waste surface to the bottom of the tank, less 07 feet for the length of the probe A smaller WATER DEPTH value can be inputted if a narrow span is desired

TIME This settıng determines the maxımum time that the instrument will allow for profiling, as well as the frequency of measurement cycles The setting can be calculated by multiplying the total depth (DIST TO WATER + WATER DEPTH) tımes the profiler travel speed, (0 1 minutes per foot), and adding 1 minute (a built in delay after the profile is 
initiated) A conservative value of 50 was input for the testing since the maxımum depth profiled was 325 feet Calculatıng the depth settıng would give $325 \times 01+1=425$ minutes

SETPONT This settıng represents the maxımum solıds concentration that will be profiled The settıng can be used to detect a specific sludge layer of a known concentration A maximum settıng of 99 was used during the test, since only the detection of the maximum solids concentration is of interest

ADDRRESS This setting is used to configure alarms for high sludge or high clarity readings A default settıng of 50 was used during the test since the alarm feature is not required for this application

The SSP was run through an initial setup sequence with settıngs input as described above The SSP was then operated in the manual mode to demonstrate that the probe would travel to the estımated DIST TO WATER and WATER DEPTH settings The position of the probe at the DIST TO WATER setting which is where the initial profile reading will be taken, was 'tnmmed using the control knob to completely submerge the probe This was performed to demonstrate the ability to fine tune the probe elevation

\section{SSP PROFIING OPERATION}

This phase of testing was performed to demonstrate the operation of the SSP in the profiling mode The SSP was operated in the AUTO mode using the rake switch to initiate the profiling sequence In the profiling mode the probe is lowered to the DIST TO WATER settıng where the first profile reading is taken and then continues to take profile readings at 19 additional equally spaced elevations The last reading is taken at a depth defined by the WATER DEPTH settıng, before the probe is retracted automatically The probe contınues to be retracted unth it contacts a plate located below the cable reel in the glove box which automatically shuts off the cable reel motor

\section{SUSPENDED SOLIDS READING CALIBRATION}

This test phase was performed to calibrate the accuracy of the profiler suspended solids concentration readings Increasingly dilute samples of the waste simulant were profiled to measure their suspended solids concentrations Readings were displayed at the PC and recorded The suspended solids concentration of tap water was measured initially to establish a baseline Subsequent suspended solids measurements were then obtained from a full strength sample of the waste simulant, and from six other samples, each of which was diluted by $50 \%$ from the previous sample Representative portions of each sample were then obtained and analyzed to determine the actual solids concentration The actual and measured concentrations were then compared and a calibration factor was calculated 


\section{ELEVATION CALIBRATION}

This test phase was performed to determine the accuracy and calibration of elevation settings input in the SSP and elevation readings displayed at the PC As discussed previously, the SSP will take 20 equally spaced profile measurements beginning with an initial reading at the DIST TO WATER settings with the remainder of the readings taken in the span defined by the WATER DEPTH settıng Separate test sequences were performed to calibrate elevation settings and readings in both the manual mode and automatic (profilıng) mode

The first test sequence was performed while operatıng the SSP in the manual mode The probe was lowered with various values for DIST TO WATER inputted, and the WATER DEPTH set to 0 In this configuration the probe automatically stops at the DIST TO WATER setting, and the actual distance that the probe travels is measured and recorded The distance that the probe has traveled is also displayed on the PC screen and documented

The second test sequence was the same as the previous sequence except that values other than 0 for WATER DEPTH were inputted The probe automatically stops at the total depth setting (the sum of the DIST TO WATER and WATER DEPTH) and once again that actual probe travel distance was measured and recorded as well as the values displayed on the PC

In the third and final sequence values were once again input for DIST TO WATER and WATER DEPTH, however now the SSP was operated in the profiling or AUTO mode The distance to the initial profile elevation input as DIST TO WATER, and to the final profile elevation or total depth reading were recorded as the probe stopped to take its initial and final readings

\section{WASH RING FUNCTIONAL OPERATION TESTING}

The SSP assembly is equipped with a water spray ring that decontamınates the probe and cable as it is being retracted A solenoid valve that is installed between the water supply and the wash ring controls the spray wash The solenoid will automatically open when the SSP is raised, and will automatically close when the stepper motor is stopped This washing function will perform whenever the probe is raised, etther manually using the control knob or automatically after a profiling sequence

Water was supplied to the spray ring assembly at approxımately 80-psı from the bulding water supply The SSP was suspended over a tub to collect the spray water To test the operation of the wash ring assembly, the probe was lowered to the floor and then raised by manually setting the control knob to the RAISE position The probe was allowed to be raised until it automatically stopped at the contact plate 


\section{TEST RESULTS}

\section{MANUAL OPERATION}

Functional testing of the SSP in the manual mode was performed successfully The probe was lowered and raised using the manual control knob at the SSP by switching to the LOWER or RAISE positions, respectively The probe could be stopped at any position by switching the control knob to the STOP position This procedure of lowering, stopping and raising the probe was used to "tnm" the probe to the correct depth of water setting The probe was also lowered in the manual mode to a preset elevation by dialing in values for DIST TO WATER and WATER DEPTH at the rotary switches In this application, the control knob was set to LOWER and left in that position until the probe stopped automatically at the sum of the DIST TO WATER and WATER DEPTH settings This procedure was tried numerous times at the same depth settıng, and each tıme the probe stopped at the same elevation within \pm 1 inch In all sequences, when the probe was retracted the cable reel stepper motor stopped automatically when it touched the contact plate at the reel

\section{AUTOMATIC OPERATION}

Functional testing of the SSP in the automatic profiling mode was performed successfully The profile operation was initiated remotely by closing and opening the rake switch located at the PC The probe was lowered automatically to the DIST TO WATER settıng where the first profile reading was taken The probe then contınued to be lowered to nineteen additional equally spaced locations that spanned the WATER DEPTH setting Profile readings at each location were displayed on the PC screen The location of the probe relative to the initial starting position (distance traveled) was also displayed on the PC screen

\section{SUSPENDED SOLIDS READING CALIBRATION}

Seven test samples of varying suspended solıds particle concentration were made up for calibration testing of the SSP The initial test sample was tap water and the remaining samples were made from the waste simulant slurry described in Section 23 The slurry was first measured at full concentration, and was then diluted by $50 \%$ each time for subsequent samples The suspended solids concentration of the samples was to be determined by analysis at the 306 building before being measured by the SSP However, due to the unavalability of resources the analysıs was performed after testıng The Benton-Franklın Publıc Health Department laboratory was used to analyze the samples and the results are shown in Appendix B 
Table 1

\begin{tabular}{|c|l|l|l|}
\hline $\begin{array}{c}\text { Sample } \\
\text { No }\end{array}$ & Composition & $\begin{array}{l}\text { SSP } \\
\text { Readıng, } \\
\text { Ppm }\end{array}$ & $\begin{array}{l}\text { Laboratory Analysis } \\
\text { Total Suspended Solıds } \\
\text { mg/L }\end{array}$ \\
\hline 1 & Tap Water & 3 & 0 \\
\hline 2 & Simulant, full strength & 19,672 & 111,140 \\
\hline 3 & Simulant diluted to $50 \%$ & 24,248 & 50,650 \\
\hline 4 & Simulant diluted to $25 \%$ & 21,240 & 21,850 \\
\hline 5 & Simulant diluted to $125 \%$ & 13151 & 10,533 \\
\hline 6 & Simulant diluted to $62 \%$ & 8,008 & 5,060 \\
\hline 7 & Simulant diluted to 31\% & 2,260 & 2,480 \\
\hline
\end{tabular}

The results of the analysis and testing are shown in Table 1 Examination of the data shows that the SSP operated favorably at the more dilute sample concentrations and less favorably as the sample concentrations that approached the upper profiling range of the sensor The SSP measurement range per the manufacturer, is typically from $5 \mathrm{ppm}$ to $60,000 \mathrm{ppm}(6 \%)$ Tap water which when analyzed did not show the presence of any suspended solids (sample No 1) was profiled initially to serve as a baseline The SSP reading of $3 \mathrm{ppm}$ is well within the accuracy of the sensor Tap water was also profiled at the end of the testing with the same results Sample No 2, which contained a suspended solids concentration of over $9 \%$, did not provide an accurate measurement as expected since the sample concentration was outside of the range of the sensor Sample No 3 produced an SSP reading of $24248 \mathrm{ppm}$ which is lower than what might be expected for a suspended solids concentration estımated at approxımately $46 \%$ (the density of the slurry was assumed to be 11 ) The concentration of this sample may also have approached the actual upper range of the instrument resulting in an erroneous reading Samples 4 through 7 produced farrly consistent results $A$ plot of the SSP readings versus the sample concentration determined from the laboratory analysis (excluding the Sample No 2 reading) is shown in Figure B-1 (Appendix B) As with any turbidity monitor, if the SSP is used for anything other than a relative measurement, it is necessary to compare the readings to the actual total suspended solids content from samples In practice, a correlation should be developed by comparing the SSP readings to actual sludge concentrations obtained by sample analysis 


\section{ELEVATION READING CALIBRATION}

Calibration of the SSP rotary dial settings and the computer screen probe depth readings were completed successfully Calibration factors for both measurements were obtained as described in Sections 442 and 443

\section{Distance Measurement}

The distance that the probe traveled was measured by using a standard steel tape The contact plate at the SSP enclosure was used as a reference point for the readings The probe was marked at the spot where it touched the contact plate in the retracted position as a reference point on the probe The actual distance traveled when the probe was lowered was measured by holding the end of the tape at the mark on the probe and measuring the tape distance at the contact plate

The maximum distance from the SSP probe in the fully retracted position to the floor was approximately 35 feet Thus, distance could be measured directly for probe travel distances of less than 35 feet For distances greater than 35 feet travel distances were measured in two parts The procedure for making these measurements was to first lower the probe until such time that it came close to the floor Then, without stopping the lowering of the probe, tension was applied by a constant pull on the cable while the remainder of the cable was let out and the probe rested on the floor To obtain the total travel distance, a mark was made on the cable at some point where a direct measurement could be made between the mark and the contact plate, and the distance was recorded The remaining cable with the probe attached was stretched horizontally, and a second measurement was taken between the mark on the cable and the reference mark on the probe The total distance traveled was the sum of these two measurements The accuracy for these measurements is estımated at approxımately $\pm 1 / 2$ inch

\section{SSP Rotary Dıal Setting Calıbratıon}

Testıng to calibrate rotary dial settıngs was performed both in the manual mode and in the automatic profiling mode Actual measured distances were recorded for various values and combinations of DIST TO WATER and WATER DEPTH settıngs (see Table 2) The SSP settings were then plotted against the measurements for actual distance that the probe traveled The resulting graph is shown in Figure B-2 (Appendix B) As seen from the plot, the relationship between the two parameters is linear resulting in a simple calibration factor, $1 \mathrm{e}$ the SSP setting is 108 times the actual distance In practice, the calibration factor would be multuphed times the distance required to obtain the correct SSP setting For example, if the actual distance to water is 30 feet, the correct DIST TO WATER setting to obtain that distance would be 30 times 108 or 324 
Table 2

\begin{tabular}{|c|c|c|c|c|c|c|c|c|c|}
\hline & & & \multicolumn{2}{|c|}{ SSP SETTINGS } & & \multicolumn{2}{|c|}{$\begin{array}{l}\text { MEASURED } \\
\text { VALUES }\end{array}$} & & \\
\hline 1 & 2 & 3 & 4 & 5 & 6 & 7 & 8 & 9 & 10 \\
\hline No & $\begin{array}{c}\text { Test } \\
\text { Section }\end{array}$ & Mode & $\begin{array}{c}\text { DISTANCE } \\
\text { TO } \\
\text { WATER(f) } \\
\end{array}$ & $\begin{array}{c}\text { WATER } \\
\text { DEPTH } \\
\text { (fe) } \\
\end{array}$ & $\begin{array}{l}\text { Total } \\
\text { Depth } \\
(4+5)(4\end{array}$ & $\begin{array}{c}\text { Distance } \\
\text { to water } \\
(\mathrm{ft})\end{array}$ & $\begin{array}{l}\text { Total } \\
\text { Depth } \\
(f \in) \\
\end{array}$ & $\begin{array}{l}\text { Offset } \\
(7-4) \\
(f(t)\end{array}$ & $\begin{array}{l}\text { Offset } \\
(8-6) \\
(f(t)\end{array}$ \\
\hline 1 & 2414 & $\mathbf{M}$ & 250 & 000 & 250 & $\begin{array}{r}232 \\
228^{l}\end{array}$ & NA & $\begin{array}{ll}(1 & 8 \\
0 & 4^{2}\end{array}$ & NA \\
\hline 2 & 2414 & $\mathbf{M}$ & 275 & 000 & 275 & $\begin{array}{l}255 \\
252^{1} \\
\end{array}$ & NA & $\begin{array}{l}\left(\begin{array}{ll}2 & 0\end{array}\right) \\
03^{2}\end{array}$ & NA \\
\hline 3 & 2414 & $\mathbf{M}$ & 300 & 000 & 300 & $\begin{array}{r}278 \\
275^{1} \\
\end{array}$ & NA & $\begin{array}{l}\left(\begin{array}{ll}2 & 2\end{array}\right) \\
03^{2}\end{array}$ & NA \\
\hline 4 & 2414 & $\mathbf{M}$ & 325 & 000 & 325 & $\begin{array}{l}301 \\
299^{1}\end{array}$ & NA & $\begin{array}{l}\left(\begin{array}{ll}2 & 4\end{array}\right) \\
0\end{array}$ & NA \\
\hline 5 & 2414 & $\mathbf{M}$ & 400 & 000 & 400 & $\begin{array}{l}370 \\
\text { NA }\end{array}$ & NA & $(30)$ & NA \\
\hline 6 & 2414 & $\overline{\mathbf{M}}$ & 500 & 000 & 500 & $\begin{array}{l}461 \\
474^{1}\end{array}$ & NA & $\begin{array}{c}\left(\begin{array}{ll}3 & 9\end{array}\right) \\
(13)^{2}\end{array}$ & NA \\
\hline & 2414 & $\mathbf{M}$ & 600 & 000 & 600 & $\begin{array}{r}555 \\
584^{l} \\
\end{array}$ & NA & $\begin{array}{l}(45) \\
(26)^{2} \\
\end{array}$ & $\mathrm{NA}$ \\
\hline & & & & & & & & & \\
\hline 7 & 2423 & $\mathbf{M}$ & 50 & 200 & 250 & NA & $\begin{array}{l}233 \\
228^{\prime}\end{array}$ & NA & $\begin{array}{l}(17) \\
05^{3}\end{array}$ \\
\hline 8 & 2423 & $\mathbf{M}$ & 50 & 225 & 275 & NA & $\begin{array}{r}256 \\
252^{\prime} \\
\end{array}$ & NA & $\begin{array}{l}\left(\begin{array}{ll}1 & 9\end{array}\right) \\
04^{3}\end{array}$ \\
\hline 9 & 2423 & $\mathbf{M}$ & 50 & 250 & 300 & $\overline{\mathbf{N A}}$ & $\begin{array}{r}278 \\
275^{1} \\
\end{array}$ & NA & $\begin{array}{cc}\left(\begin{array}{ll}2 & 2\end{array}\right) \\
0\end{array} 3^{3}$ \\
\hline 10 & & & 200 & 200 & 400 & NA & $\begin{array}{l}371 \\
374^{1}\end{array}$ & NA & $\begin{array}{c}(29) \\
(03)^{3}\end{array}$ \\
\hline 11 & & & 300 & 300 & 600 & NA & $\begin{array}{r}557 \\
584^{\prime} \\
\end{array}$ & NA & $\begin{array}{l}(43) \\
(27)^{3} \\
\end{array}$ \\
\hline 15 & 24210 & $\overline{\mathbf{A}}$ & 250 & 50 & 300 & $\begin{array}{ll}23 & 1 \\
22 & 8^{1} \\
\end{array}$ & $\begin{array}{l}278 \\
275^{\prime} \\
\end{array}$ & $\begin{array}{r}\left(\begin{array}{ll}1 & 9\end{array}\right) \\
03^{2}\end{array}$ & $\begin{array}{l}(2) \\
03^{3} \\
\end{array}$ \\
\hline 16 & 24210 & $\mathbf{A}$ & 250 & 50 & 300 & $\begin{array}{r}231 \\
228^{1} \\
\end{array}$ & $\begin{array}{r}278 \\
275^{\prime} \\
\end{array}$ & $\begin{array}{cc}\left(\begin{array}{ll}1 & 9\end{array}\right) \\
0 & 3^{2}\end{array}$ & 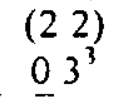 \\
\hline 17 & 24210 & $\mathbf{A}$ & 275 & 50 & 325 & $\begin{array}{r}254 \\
252^{\prime}\end{array}$ & $\begin{array}{l}301 \\
299^{\prime}\end{array}$ & $\begin{array}{ll}\left(\begin{array}{ll}2 & 1\end{array}\right) \\
0 & 2^{2}\end{array}$ & $\begin{array}{cc}\left(\begin{array}{ll}2 & 4\end{array}\right) \\
0 & 2^{3}\end{array}$ \\
\hline
\end{tabular}

${ }^{1}$ Computer screen reading

${ }^{2}$ Offset is distance between measured readings and computer screen reading (column 7)

${ }^{3}$ Offset is distance between measured readings and computer screen reading (column 8 ) 
During the course of the testing, several measurements were repeated for the same depth values These measurements are shown in Table 3 Comparison of the measurements shows that the maximum deviation of measured values from the average is 1-1/4 inches This deviation is well within the manufacturers accuracy of 01 inches per foot of depth

Table 3

\begin{tabular}{|c|c|c|c|c|c|c|c|}
\hline $\begin{array}{l}\text { SSP } \\
\text { Setting }\end{array}$ & $250^{\prime}$ & $275^{\prime}$ & $300^{\prime}$ & $325^{\prime}$ & $400^{\prime}$ & 500 & 600 \\
\hline \multirow[t]{4}{*}{$\begin{array}{l}\text { Measured } \\
\text { Distance }\end{array}$} & $23^{\prime}-2^{3 / 4}$ & $25^{\prime}-6^{\prime \prime}$ & 27-91/2" & $30^{\prime}-1 \frac{1}{1 / 2}$ & $\begin{array}{l}36^{\prime}- \\
11^{3 / 4} "\end{array}$ & $46^{\prime}-0^{3 / 4}$ & $55-81 / 2$ \\
\hline & $23^{\prime}-33^{1 / 2}$ & $25^{\prime}-7^{\prime \prime}$ & $27^{\prime}-10^{\prime \prime}$ & $30^{\prime}-11 \frac{1}{2 \prime}$ & $37^{\prime}-03 / 4$ & & $55-6$ \\
\hline & $23-11 / 2 "$ & $25^{\prime}-5^{\prime \prime}$ & $27^{\prime}-91 / 2 "$ & & & & \\
\hline & $23-11 / 2^{\prime \prime}$ & & $27^{\prime}-9^{\prime \prime}$ & & & & \\
\hline Average & $23^{\prime}-25 / 16^{\prime \prime}$ & $25^{\prime}-6 "$ & $27^{\prime}-91 / 2 "$ & $30^{\prime}-13 / 8^{\prime \prime}$ & $37^{\prime}-0^{1 / 4^{\prime}}$ & $46-0^{3 / 4}$ & $55 \quad 7$ \\
\hline $\begin{array}{l}\text { Maximum } \\
\text { Deviation }\end{array}$ & $13 / 16^{\prime \prime}$ & 1" & $1 "$ & $1 / 8$ & $1 / 2$ & $0^{\prime}$ & $11 / 4$ \\
\hline
\end{tabular}

\section{Computer Screen Probe Depth Reading Calıbration}

The SSP software will display the current location of the probe on the computer on an Alphanumeric Screen The probe depth will contınually change while the probe 18 ether raised or lowered During calibration testing of the SSP settıngs probe depth readings, as displayed on the alphanumeric screen, were recorded The probe depth readings were plotted against the measurements for actual probe travel distance The resulting graph is shown in Figure B-3 (Appendix B) As seen from the plot, the relationship between the two parameters is also linear, however, also contains an offset value In practice, the actual probe location could be found by multiplying the probe depth reading as viewed on the computer screen by the calibration factor and then adding the offset For example, if the computer displays a probe depth of 282 feet, the actual distance would be (0 912 times 282 ) +2593 or 288 feet

The actual position of the probe can also be calculated by another method using the DIST TO WATER and WATER DEPTH settıngs The probe will take its first profile reading at the DIST TO WATER settıng The actual depth at this position can be found by multıplyıng the settıng by the Rotary Dial calıbration factor discussed in Section 43 The subsequent profile locations can be found by multiplying the WATER DEPTH setting by the Rotary Dial calıbration factor to obtain the correct profiling span, and then dividing by 19 to obtain the increment depth 
The manufacturer states that the probe depth is generally uncalibrated at the factory and that it is most useful as an indication of whether or not the instrument is currently profiling It is recommended that both methods for determining the actual probe location be used and compared for providing the best results

\section{SPRAY WASH SYSTEM}

Functional testıng of the SSP spray wash system was performed successfully The solenoid valve opened and operation of the spray ring began as soon as the control knob was switched to the RAISE position The spray continued until the probe was fully retracted Upon touching the contact plate the cable reel motor turned off and the solenoid valve closed 


\section{CONCLUSIONS AND RECOMMENDATIONS}

The Suspended Solids Profiler instrument operated correctly durıng both the manual and automatic profiling modes It is recommended that the SSP be installed on Tank AZ-101 and full scale testing be performed as part of the mixer pump test 
RPP-5522 Rev 0

Appendix A

A-1 